\title{
A RESPONSABILIDADE CIVIL PELOS RISCOS DO DESENVOLVIMENTO NO ORDENAMENTO JURÍDICO BRASILEIRO
}

\author{
CIVIL LIABILITY FOR THE RISKS OF DEVELOPMENT IN BRAZILIAN LEGAL \\ ORDER
}

\author{
José Laurindo de Souza Netto ${ }^{1}$ \\ Adriane Garcel $^{2}$ \\ Gustavo Calixto Guilherme ${ }^{3}$
}

\section{RESUMO}

O presente artigo objetiva investigar a aplicabilidade da teoria da responsabilidade civil do fornecedor pelos riscos do desenvolvimento no ordenamento jurídico brasileiro. A problemática está na ausência de previsão legal no Código de Defesa do Consumidor dos riscos do desenvolvimento como hipótese de excludente de responsabilidade civil do fornecedor. A pesquisa justifica-se tendo em vista que na União Europeia, como regra geral, os riscos do desenvolvimento são tratados como hipótese de excludente de responsabilidade. A metodologia utilizada baseia-se em uma análise doutrinária e jurisprudencial que apresenta, inicialmente, os princípios constitucionais, os conceitos e a responsabilidade civil no Código de Defesa do Consumidor. Em um segundo momento, são abordadas a teoria dos riscos do desenvolvimento, a Diretiva 85/374 da Comunidade Econômica Europeia, os posicionamentos doutrinários e os julgados dos Tribunais sobre o assunto. $\mathrm{O}$ artigo conclui que, apesar da omissão legislativa, o fornecedor de produtos deve responsabilizar-se pelos riscos do desenvolvimento, não podendo ser tratados como hipótese de exclusão de responsabilidade, tendo em vista a primazia pela observância dos princípios constitucionais e pela tutela do consumidor.

PALAVRAS-CHAVE: CONSTITUCIONAL. CONSUMIDOR. RESPONSABILIDADE CIVIL. RISCOS DO DESENVOLVIMENTO. APLICABILIDADE.

\begin{abstract}
This article aims to investigate the applicability of the supplier's liability theory for development risks in the Brazilian legal system. The issue is in the absence of legal provision in the Consumer Protection Code of development risks as a possibility of exclusion of supplier's liability. The research is justified in view of in European Union the risks of development are a kind of liability excluder. The methodology used is based on a doctrinal and jurisprudential analysis that presents, initially, the constitutional principles, the concepts and civil responsability in the Consumer Protection Code. Secondly, the theory of development risks, the

\footnotetext{
${ }^{1}$ Pós-doutor pela Faculdade de Direito da Universidade Degli Studi di Roma La Sapienza. Estágio de Pósdoutorado em Portugal e Espanha. Mestre e Doutor pela Universidade Federal do Paraná - UFPR.

${ }^{2}$ Mestranda em Direito Empresarial e Cidadania no Centro Universitário de Curitiba - UNICURITIBA. Pósgraduada em Direito Aplicado pela Escola da Magistratura do Paraná - EMAP e FEMPAR.

${ }^{3}$ Especialista em direito processual civil pelo Centro de Estudos Jurídicos Prof. Luiz Carlos. Graduado em Direito pela Universidade Positivo e em Administração pela Universidade Federal do Paraná - UFPR.
} 
Directive 85/374 of the European Economic Community, the doctrinal positions and the judgments of the courts about the subject are discussed. The article concludes that, despite the legislative omission, the product supplier must be responsible for the risks of development, in view of the primacy for the observance of constitucional principles and consumer protection.

KEY WORDS: CONSTITUTIONAL. CONSUMER. CIVIL LIABILITY. RISKS OF DEVELOPMENT. APPLICABILITY.

\section{CONSIDERAÇÕES INICIAIS}

O avanço tecnológico e científico presenciado nas últimas décadas ocasionou grandes mudanças na sociedade, erigindo o consumidor a um patamar de protagonismo.

Nesse panorama, tornou-se necessária a criação de normas para reger a relação consumerista, bem como para tutelar os indivíduos expostos aos acidentes de consumo. Dessa forma, o ordenamento jurídico evoluiu em busca da garantia dos direitos fundamentais do indivíduo e, entre as normativas criadas, foi promulgada a Lei ${ }^{\circ}$ 8.078/1990, sendo criado o Código de Defesa do Consumidor para estabelecer direitos e deveres a serem seguidos na relação de consumo.

Entre os diversos dispositivos presentes no Código, as excludentes de responsabilidade merecem especial relevo, tendo em vista a existência de uma lacuna legislativa quanto a responsabilidade civil do fornecedor pelos riscos do desenvolvimento, hipótese de excludente utilizada em outros ordenamentos, como por exemplo nos países da União Europeia.

O presente artigo objetiva apresentar justamente a teoria da responsabilidade civil do fornecedor de produtos pelos riscos do desenvolvimento e a sua aplicação na realidade brasileira.

Primeiramente o presente artigo irá abordar o Direito do Consumidor e o seu viés constitucional, por meio dos princípios e conceitos estabelecidos em lei.

Em um segundo momento, apresentar-se-á o conceito dos riscos do desenvolvimento, a responsabilidade civil no âmbito do direito do consumidor e a Diretiva 85/374 da Comunidade Econômica Europeia.

Por fim, será demonstrado de que modo tem se posicionado a doutrina e a jurisprudência sobre o tema, visando responder sobre a aplicação dos riscos do desenvolvimento nas relações de consumo. 
A constitucionalização do Direito produz impactos relevantes em todos os ramos jurídicos. No direito civil, além da Constituição estabelecer princípios e regras que repercutem nas relações privadas, como por exemplo na proteção do consumidor, houve o impacto revolucionário do princípio da dignidade humana. (BARROSO, 2013, p. 33).

Assim, o estudo do Código de Defesa do Consumidor deve passar por uma análise dos princípios constitucionais, vez que devem nortear a interpretação da legislação consumerista (THEODORO JÚNIOR, 2017, p. 24).

Como direito fundamental, a defesa do consumidor está prevista no ordenamento jurídico brasileiro no artigo $5^{\circ}, \mathrm{XXXII}$, da Constituição Federal, o que o coloca a salvo da possibilidade de reforma pelo poder constituinte instituído. (MIRAGEM, 2018, p. 60).

Isso significa que o Estado deve ter uma atuação positiva, através de todos os seus poderes (Legislativo, Executivo e Judiciário), visando a proteção deste direito fundamental, direito humano de nova geração, social e econômico (BENJAMIN; BESSA; MARQUES, 2014, p. 35).

A defesa do consumidor também está estabelecida como um dos princípios da ordem econômica e financeira da Carta Magna, estabelecida no artigo 170, V, do texto constitucional, que prevê que a ordem econômica tem por fim assegurar a existência digna, conforme os ditames da justiça social, observados, entre outros princípios, a defesa do consumidor.

A aferição da legitimidade dos fins a que a ordem econômica deve respeitar e está atrelada ao princípio maior da dignidade da pessoa humana, conformador do conceito de Estado Democrático de Direito consagrado na Constituição (MIRAGEM, 2018, p. 68).

Dessa forma, sendo a proteção do consumidor um direito fundamental e o Código de Defesa do Consumidor uma norma de origem constitucional, vez que a Lei $\mathrm{n}^{\circ}$ 8.078/90 foi criada por meio do artigo 48 do Ato das Disposições Constitucionais Transitórias, a relação de consumo deve ser tutelada por todos os dispositivos da Constituição, como por exemplo o direito à vida, à saúde e à dignidade da pessoa humana.

\subsection{OS PRINCÍPIOS DO DIREITO DO CONSUMIDOR}

Princípios são disposições que devem ser seguidas, formando a base, o ponto de partida para a análise de todo o ordenamento jurídico e para onde ele se norteia (CAVALIERI FILHO, 2010, p. 29). Eles são verdades estruturantes de um sistema jurídico, assim admitidas, não só 
por serem evidentes ou terem sido comprovadas, mas também por motivos práticos (REALE, 1995, apud CAVALIERI FILHO, 2010, p. 31).

A Política Nacional de Consumo deve atender os princípios estabelecidos no artigo $4^{\circ}$ do Código de Defesa do Consumidor. Tais princípios encontram fundamento no texto constitucional, mas são regulados pela codificação consumerista, a fim de estimular uma relação saudável entre consumidores e fornecedores (THEODORO JÚNIOR, 2017, p. 27).

Entre os diversos princípios do Código, as verdades estruturantes a serem seguidas na relação de consumo e que merecem destaque são: o princípio da boa-fé, da informação ou transparência, da garantia da adequação, do dever governamental, do acesso à justiça e o da vulnerabilidade

De início, o princípio da boa-fé visa regulamentar as relações de consumo em um sentido ético, que seja adequado para ambas as partes do negócio jurídico.

O princípio da boa-fé é considerado o mais importante no plano infraconstitucional, assim como o princípio da dignidade da pessoa humana é no plano constitucional (CAVALIERI FILHO, 2010, p. 35).

A boa-fé é citada no Código de Defesa do Consumidor no artigo $4^{\circ}$, inciso III, que trata de estabelecer o equilíbrio na relação consumerista e a harmonização dos interesses entre os participantes das relações de consumo.

Já o princípio da transparência significa a informação clara e correta sobre o produto a ser vendido, sobre o contrato a ser firmado, significa lealdade e respeito nas relações entre fornecedor e consumidor, possibilitando uma aproximação e uma relação contratual mais sincera e menos danosa entre consumidor e fornecedor (MARQUES, 2006, p. 714-715).

O dever de informação pode configurar-se de modo educacional, no sentido de conscientizar os consumidores na busca de seus interesses. Desse modo, o princípio pode ser interpretado de várias formas, sempre visando à efetivação dos interesses do consumidor (EFING, 2008, p. 106).

A princípio da garantia da adequação está disposto no artigo $4^{\circ}$, II, e no artigo 24 do Código, sendo que o fornecedor deve ser o protagonista para efetivar a adequação dos produtos e serviços à demanda pela saúde, segurança, qualidade de vida e demais bens jurídicos afetos aos consumidores (EFING, 2008, p. 108).

Em uma abordagem mais contratual, tal garantia impede que se estipulem cláusulas contratuais que impossibilitem, exonerem ou mesmo atenuem as obrigações pelos vícios de inadequação, dispostas nos artigos 18 a 25 do CDC (MARQUES, 2006, p. 1178). 
A garantia da adequação está vinculada ao princípio do dever governamental, presente no artigo $4^{\circ}$, incisos II,VI e VII do Código de Defesa do Consumidor, que dispõe a importância da ação governamental no sentido de proteger efetivamente o consumidor, por iniciativa direta, por incentivos à criação e desenvolvimento de associações representativas, pela presença do Estado do mercado de consumo, pela garantia dos produtos e serviços com padrão adequados de qualidade, segurança, durabilidade, desempenho entre outras medidas de tutela.

Outro princípio de grande relevância é o do acesso à justiça, tratado na legislação consumerista e advindo do texto constitucional, como direito fundamental do artigo $5^{\circ}$, inciso XXXV da Carta Magna: “a lei não excluirá da apreciação do Poder Judiciário lesão ou ameaça a direito".

Por fim, e se tratando de equilíbrio da relação de consumo, é de extrema importância ressaltar o princípio da vulnerabilidade.

Elencada no artigo $4^{\circ}$, inciso I do CDC, o princípio da vulnerabilidade é a base do Código e visa estabelecer um equilíbrio entre a relação do fornecedor, dono do meio de produção, com o consumidor, elo mais fraco da relação de consumo, que na maioria das vezes não possui conhecimentos técnicos e específicos dos bens colocados à sua disposição (THEODORO JÚNIOR, 2017, p. 28).

Importante ressaltar que além dos princípios elencados, o Código garante uma série de direitos básicos ao consumidor, como a proteção à vida, à saúde, à segurança, a proteção contra a publicidade enganosa, a informação adequada e clara sobre os diferentes produtos e serviços, a efetiva prevenção e reparação de danos patrimoniais e morais, individuais, coletivos e difusos, entre outros direitos previstos no artigo $6^{\circ}$ da Lei 8.078/90.

Dessa forma, o Código estabelece uma série de princípios e garantias fundamentais que irão reger a relação de consumo.

\subsection{A RELAÇÃO DE CONSUMO}

Para que sejam aplicados os princípios e o microssistema normativo do Código de Defesa do Consumidor, deverá ser primeiramente verificada a existência de uma relação de consumo, tendo em um lado o fornecedor de produtos ou serviços e no outro lado o consumidor, estando presente sua vulnerabilidade.

O conceito de consumidor é abordado no artigo $2^{\circ}$ da Lei 8.078/90, sendo toda a pessoa física ou jurídica que adquire ou utiliza produto ou serviço como destinatário final, 
equiparando-se a consumidor a coletividade de pessoas, ainda que indetermináveis, que haja intervindo nas relações de consumo.

Apesar da objetividade do Código, a interpretação do que seria utilizar o produto ou serviço como destinatário final gerou o surgimento de duas teorias para entender quem é consumidor no sistema jurídico brasileiro, e dessas duas teorias surgiu uma terceira, que é a mais adotada na prática.

A primeira teoria, denominada finalista, restringe a conceituação, sendo o destinatário final somente aquele que retira o bem ou produto do mercado, dando-lhe uma destinação pessoal, sem qualquer interesse pessoal (THEODORO JÚNIOR, 2017, p. 06).

A corrente de interpretação maximalista, sustenta que a definição deve ser interpretada extensivamente, como o destinatário fático do produto ou serviço, ainda que não seja necessariamente seu destinatário econômico, ou seja, basta que se adquira ou utilize o produto ou serviço, não sendo necessário que sejam retirados do mercado ou que não sejam reempregados na atividade econômica (MIRAGEM, 2018, p. 180).

A terceira corrente, denominada de teoria do finalismo aprofundado ou mitigado é a que predomina atualmente na jurisprudência do Superior Tribunal de Justiça, considerando o consumidor através de uma condição de vulnerabilidade, podendo esta ser técnica, jurídica, fática ou até mesmo informacional (BENJAMIN; BESSA; MARQUES, 2014, p. 103-105).

A vulnerabilidade técnica diz respeito à falta de conhecimentos específicos sobre o produto adquirido, a jurídica se caracteriza pela falta de conhecimentos jurídicos ou científicos, a fática é analisada em relação ao fornecedor, quando se encontra em posição de monopólio, fático ou jurídico e a informacional ocorre quando do déficit informacional do cliente, atingido, muitas vezes, pela manipulação das informações prestadas (THEODORO JÚNIOR, 2017, p. 08-09).

No que se refere ao fornecedor, o conceito está previsto no artigo $3^{\circ}$ da legislação consumerista e possui um conceito bem amplo. O Código de Defesa do Consumidor quis enquadrar como fornecedor todo aquele que "desenvolva atividades" econômicas no mercado (KHOURI, 2009, p. 46).

O Estado também pode atuar como fornecedor de serviços, quando presta serviços aos contribuintes, nos termos do artigo 22 do Código: “Os órgãos públicos, por si ou suas empresas, concessionárias, permissionárias ou sob qualquer outra forma de empreendimento, são obrigados a fornecer serviços adequados, eficientes, seguros e, quanto aos essenciais, contínuos". 
Como construção doutrinária existe a figura do fornecedor por equiparação, em que o fornecedor-equiparado seria um terceiro na relação de consumo, um intermediário auxiliar da relação principal de consumo, mas que atua frente a um consumidor, como por exemplo, a empresa de banco de dados que insere o consumidor em seu cadastro de inadimplentes pelo suposto não pagamento de um produto (BENJAMIN; BESSA; MARQUES, 2014, p. 124).

É importante ressaltar que as normas do Direito do Consumidor só serão aplicadas quando o fornecimento de produtos e serviços estiver perante a relação de consumo enquadrada nos conceitos vistos nessa seção.

\subsection{A RESPONSABILIDADE CIVIL DO FORNECEDOR NAS RELAÇÕES DE CONSUMO}

A responsabilidade, no âmbito jurídico, significa o dever de a pessoa obrigar-se por algo que fez ou deixou de fazer quando devia agir. Por ação ou omissão o agente responderá ou perante padrões de conduta estabelecidos em lei como crime, ou por ofensa à legislação não penal, com o propósito de obrigar à reparação do dano material ou moral causado a outrem (STOCO, 2011, p. 140).

A responsabilidade civil envolve, antes de tudo, o dano, o prejuízo, o desequilíbrio ou descompensação do patrimônio de alguém (STOCO, 2011, p. 141).

O instituto da responsabilidade civil está previsto no artigo 186 do Código Civil, que estabelece que "aquele que, por ação ou omissão voluntária, negligência ou imprudência, violar direito e causar dano a outrem, ainda que exclusivamente moral, comete ato ilícito".

No título IX do respectivo Código, intitulado como "Da Responsabilidade Civil”, encontramos o artigo 927: "aquele que, por ato ilícito (arts. 186 e 187), causar dano a outrem, fica obrigado a repará-lo".

A análise do artigo 186 do Código Civil evidencia que são quatro os elementos essenciais, pressupostos da responsabilidade civil: ação ou omissão, culpa ou dolo do agente, relação de causalidade e o dano experimentado pela vítima (GONÇALVES, 2012, p. 66).

No que refere-se ao âmbito consumerista, a promulgação da Lei 8.078/90 representou não só uma revolução no que tange à responsabilidade civil, mas um divisor de águas do próprio direito brasileiro. O Código de Defesa do Consumidor é uma codificação moderna que estabeleceu o que a doutrina consagrou de microssistema jurídico e adentrou em praticamente todas as atividades negociais (VENOSA, 2018, p. 719-720). 
Os direitos do consumidor surgiram como forma de proteção do indivíduo perante o desenvolvimento que as sociedades de consumo atingiram, sendo a vulnerabilidade do consumidor a própria essência da codificação (VENOSA, 2018, p. 719-720).

Nesse sentido, a opção do Código de Defesa do Consumidor e da legislação de proteção do consumidor em todo o mundo, é o da responsabilização de natureza objetiva, dos fornecedores de produtos e serviços no mercado de consumo. (MIRAGEM, 2018, p. 601).

A alteração do sistema tradicional de responsabilidade civil baseada em culpa foi uma das grandes inovações do Código, assim, a responsabilização do réu passa a ser objetiva, já que responde independentemente de culpa pelos danos causados aos consumidores, devendo o consumidor comprovar o dano e o nexo de causalidade entre este e o produto ou serviço. (BENJAMIN; BESSA; MARQUES, 2014, p. 172-173).

Estando presentes os três requisitos supracitados (dano ao consumidor, a existência do defeito do produto ou serviço e o nexo de causalidade), a responsabilidade civil do fornecedor de produtos ou serviços será elencada em dois institutos: a responsabilidade civil pelo fato do produto e do serviço ou a responsabilidade civil pelo vício do produto ou serviço.

A responsabilidade civil pelo fato do produto e do serviço, também denominada responsabilidade por acidentes de consumo, consiste no efeito de imputar ao fornecedor, a sua responsabilização em razão dos danos causados por defeitos de concepção, produção, comercialização ou fornecimento do produto ou serviço, impondo o dever de indenizar pela violação do dever geral de segurança inerente a sua atuação no mercado de consumo (MIRAGEM, 2018, p. 602-605), possuindo respaldo nos artigos 12 e 14 do Código de Defesa do Consumidor.

Os artigos supracitados demonstram que uma série de classes de fornecedores responde objetivamente e solidariamente pelos danos causados, sendo essas classes divididas em fornecedores reais (aqueles que efetivamente participam da realização e criação do produto acabado ou parte componente, inclusive matéria prima), fornecedores aparentes (aqueles que se apresentam como fornecedores, colocando no produto seu próprio nome ou marca) e fornecedores presumidos (importadores, distribuidores e comerciantes de produtos anônimos), classificação essa segundo Marins apud EFING (2008, p. 154).

Importante destacar que diante de um acidente de consumo decorrente de um defeito que atinja a integridade física, psíquica ou até mesmo patrimonial do consumidor, a vítima terá um prazo prescricional quinquenal a partir do conhecimento do dano ou de sua autoria para reclamar em juízo, nos termos do artigo 27 do Código de Defesa do Consumidor. 
Já a responsabilidade civil pelo vício do produto ou serviço é a responsabilização diante de um defeito que, embora não cause nenhum acidente de consumo, impede seu uso potencial ou lhe diminui o valor através de anomalias que afetam a sua funcionalidade, através de vícios de qualidade ou quantidade (KHOURI, 2009, p. 193), estando o instituto previsto no artigo 18 do Código de Defesa do Consumidor.

Os vícios no produto de que se trata o artigo citado são divididos na doutrina em vícios de qualidade e quantidade (decorrentes da impropriedade ou inadequação do bem e na diminuição de seu valor) e vícios na disparidade com a oferta, que pode ocorrer pelas diferenças com as informações constantes no produto (EFING, 2008, p. 158-159), sendo que nessa última não necessariamente é preciso um dano financeiro.

No caso de vícios no serviço, entende-se pelo serviço cuja finalidade não foi atingida, seja por descaso de quem desempenhou a atividade, seja por não ter sido possível terminar a atividade (EFING, 2008, p. 159).

O Código adotou um sistema de responsabilidade civil objetiva, o que não significa dizer que é absoluto, existindo algumas causas de exclusão da responsabilidade. (BENJAMIN; BESSA; MARQUES, 2014, p. 178).

\subsection{AS EXCLUDENTES DE RESPONSABILIDADE DO CÓDIGO DE DEFESA DO CONSUMIDOR}

A análise das excludentes de responsabilidade é primordial para a tese dos riscos do desenvolvimento, visto essa hipótese não estar expressamente elencada na legislação, gerando dúvidas quanto a sua aplicabilidade em nosso ordenamento.

O fornecedor de produtos e serviços pode, de acordo com artigo $12, \S 3^{\circ}$, do Código de Defesa do Consumidor alegar que não colocou o produto no mercado ou que o defeito inexiste ou ainda que o dano foi causado por culpa exclusiva do consumidor ou de terceiro (GARCIA, 2016, p. 160).

Pela primeira excludente nota-se que a introdução do produto no mercado é pressuposto inafastável para que se cogite a responsabilidade civil por acidente de consumo. O objetivo da excludente é afastar a responsabilidade do fornecedor quando da introdução involuntária do

produto no mercado, que pode ocorrer, por exemplo, em caso de falsificação ou de roubo (CALIXTO, 2004, p. 158).

A segunda excludente que poderá ser arguida é que o produto, embora inserido no mercado, não apresenta defeito, levando-se em consideração o conceito de produto defeituoso 
estabelecido no artigo $12, \S 1^{\circ}$, do Código: o produto é defeituoso quando não oferece a segurança que dele se espera, levando-se em consideração as circunstâncias relevantes, entre as quais, a sua apresentação, o uso e os riscos que razoavelmente dele se esperam e a época em que foi colocado em circulação. Diante da inexistência de defeito, não haveria como o produto causar o acidente do consumo. (GARCIA, 2016, p. 161).

A culpa exclusiva do consumidor ou a culpa exclusiva de terceiro trata-se de hipótese de rompimento do nexo causal entre a conduta do fornecedor e o dano sofrido pelo consumidor, pelo advento de outra conduta que tenha sido realizada pelo próprio consumidor ou por um terceiro (MIRAGEM, 2018, p. 601).

Uma causa que também é discutida na questão das excludentes de responsabilidade é o caso fortuito e a força maior, que não estão elencadas no rol do artigo 12, entretanto são no direito brasileiro, em regra, excludentes de responsabilidade, podendo ser mantido, nesse caso, o sistema tradicional apto a impedir o dever de indenizar, nos moldes do que já foi julgado pelo Superior Tribunal de Justiça (BENJAMIN; BESSA; MARQUES, 2014, p. 181).

Importante o destaque de que é do fornecedor o ônus de provar a ocorrência das excludentes de responsabilidade para que seja afastado o dever de indenizar (GARCIA, 2016, p. 161).

Uma outra hipótese de afastamento da responsabilidade do fornecedor que é utilizada em alguns ordenamentos jurídicos são os riscos do desenvolvimento, que ainda não foi debatida na legislação brasileira.

\section{OS RISCOS DO DESENVOLVIMENTO E A OMISSÃO LEGISLATIVA QUANTO AO TEMA}

A responsabilidade do fornecedor quanto aos riscos do desenvolvimento é questão de grande debate na doutrina nacional. O conceito gira em torno da possibilidade de responsabilização do fornecedor quanto aos danos causados por supostos defeitos que não eram conhecidos na época da inserção do produto no mercado e que vieram a ser identificados pelo avanço técnico e científico, após causarem danos aos consumidores.

Os riscos do desenvolvimento são aqueles que são constatados apenas após o ingresso do produto ou serviço no mercado de consumo, em face de melhorias ou avanços científicos e técnicos que possibilitam a identificação do defeito já existente do produto ou serviço, mas não passível de identificação pelo fornecedor. (MIRAGEM, 2018, p. 647). 
O critério básico para que seja identificável um defeito pelo fornecedor é o estado de conhecimento da ciência e da técnica à época em que o produto foi colocado no mercado, nos moldes do artigo 12, $\S 1^{\circ}$, III, do Código de Defesa do Consumidor (MIRAGEM, 2018, p. 647).

Nesse sentido, a análise do grau de conhecimento científico não é feita tomando por base um fornecedor em particular. Importam, ao revés, as informações científicas disponíveis no mercado. Ou seja: pouco interessa o que um determinado fornecedor sabe, mas sim o que sabe a comunidade científica. (BENJAMIN; BESSA; MARQUES, 2014, p. 184).

São diversos os exemplos que podem ser dados quanto ao tema, na maioria casos de danos graves ao consumidor, como o anticolesterol MER-29, que ocasionou cegueira em algumas pessoas que o utilizaram (SILVA apud CALIXTO, 2004, p. 178) e um dos mais famosos dos casos, o do remédio Talidomida, ingerido por mulheres grávidas e que ocasionou a má-formação de milhares de crianças (SILVA apud CALIXTO, 2004, p. 178).

\subsection{A DIRETIVA 85/374/CEE}

A Comunidade Econômica Europeia, organização internacional que deu origem à atual União Europeia, por meio da Diretiva 85/374/CEE, legislou sobre a responsabilidade decorrente dos produtos defeituosos, visando orientar os seus Estados-membros quanto à questão.

$\mathrm{O}$ artigo $1^{\mathrm{o}}$ da referida Diretiva responsabiliza o produtor quanto ao dano causado por um defeito do produto: "O produtor é responsável pelo dano causado por um defeito do seu produto".

Quanto aos riscos do desenvolvimento, o direito europeu expressamente tratou como hipótese de excludente de responsabilidade por intermédio do artigo $7^{\circ}$, alínea "e" da Diretiva, ainda que tenha permitido aos países membros da Comunidade Europeia que, ao tempo em que incorporassem as regras da diretiva, pudessem derrogar a excludente (MIRAGEM, 2018, p. 648).

O artigo $7^{\circ}$, alínea “e” da Diretiva assim estabelece: “Art. $7^{\circ} \mathrm{O}$ produtor não é responsável nos termos da presente diretiva se provar: e) Que o estado dos conhecimentos científicos e técnicos no momento da colocação em circulação do produto não lhe permitiu detectar a existência do defeito".

Desse modo, o posicionamento adotado pela Comunidade Econômica Europeia é, em regra, utilizar os riscos do desenvolvimento como uma excludente de responsabilidade, 
entretanto, qualquer Estado-membro pode legislar ao contrário, prevendo em seu ordenamento a responsabilização do produtor:

\begin{abstract}
Sendo assim, entre os países europeus tem prevalecido a exclusão de responsabilidade na hipótese de riscos de desenvolvimento, podendo ser citados a Inglaterra, Irlanda, Portugal, Itália, Grécia, Dinamarca, Holanda, Áustria e Suécia (BOURGOIGNIE apud CALIXTO, 2004, p. 187). A Finlândia sempre responsabilizou o fornecedor e Luxemburgo também afastou a excludente. (COLOMER apud CALIXTO, 2004, p. 187).
\end{abstract}

Mister salientar ainda que o artigo 11 da Diretiva 85/374/CEE estabelece o prazo para a reparação dos danos causados por produtos defeituosos. $\mathrm{O}$ fornecedor do produto defeituoso responsabiliza-se pelo período de dez anos da entrada de circulação do produto, exceto se a vítima tiver ajuizada ação contra o produtor neste período, no prazo prescricional de 3 anos, a partir da data em que tomou conhecimento do dano, da identidade do produtor e do defeito, conforme artigo 10, número 1, da Diretiva.

\title{
3.2 A RESPONSABILIDADE CIVIL DO FORNECEDOR PELOS RISCOS DO DESENVOLVIMENTO NO ORDENAMENTO JURÍDICO BRASILEIRO
}

Diante da omissão legislativa sobre o tema e levando-se em conta as peculiaridades do Código de Defesa do Consumidor e os aspectos da Diretiva 85/374/CEE, surge uma indagação a ser respondida: os riscos do desenvolvimento devem ser arcados pelo fornecedor ou poderiam ser utilizados como excludente de responsabilidade civil no ordenamento jurídico brasileiro?

Para a obtenção da resposta, é de suma importância verificar o posicionamento doutrinário e as decisões do Superior Tribunal de Justiça sobre o tema.

Na doutrina, podemos identificar duas vertentes: uma sustentando que estão presentes todos os pressupostos da responsabilidade civil do fornecedor (defeito, dano e nexo causal), sendo a responsabilização uma decisão política, e outra que entende inexistente um dos pressupostos, o defeito, afastando-se, por consequência, a responsabilidade (CALIXTO, 2004, p. 200).

Adeptos da primeira vertente, Antônio Herman V. Benjamin et al. acreditam que o defeito do produto, nesses casos, é um tipo de defeito de concepção e que o sistema de responsabilidade civil objetiva não pode exonerar o fabricante, o construtor, o produtor e o importador na presença de um risco de desenvolvimento (BENJAMIN; BESSA; MARQUES, 2014, p. 182). 
Nessa toada, afirmam que a exigência moderna é no sentido de que nenhum consumidor vítima de acidente de consumo deve arcar sozinho com os seus prejuízos ou fique sem indenização, devendo o fornecedor ter a incumbência de, através dos mecanismos de preço, proceder à internalização dos custos sociais (2014, p. 183).

Outro posicionamento favorável à responsabilização do fornecedor é de Maria Parra Lucan, pela predominância da responsabilidade objetiva e pela existência do defeito no produto. Também argumenta que o momento de análise de tecnologia quando o produto é lançado no mercado se encaminha mais para proteger o fornecedor de demandas de danos causados por um produto, que quando lançado oferecia legitimamente uma segurança, do que excluir os danos ocasionados pelos riscos do desenvolvimento. (LUCAN apud CALIXTO, 2004, p. 207-208)

Nessa esteira, Cavalieri Filho entende que os riscos de desenvolvimento devem ser enquadrados como fortuito interno - risco integrante da atividade do fornecedor -, pelo que não exonerativo da sua responsabilidade (2007, p. 476).

Do mesmo modo, Bruno Miragem entende que o Código não considerou os riscos do desenvolvimento no rol do artigo que trata das excludentes de responsabilidade, bem como que é de se considerar que o legislador, ao estabelecer o regime de responsabilidade objetiva e restringir as hipóteses de exclusão teve como objetivo a máxima extensão da tutela ao consumidor contra os riscos do mercado de consumo (2018, p. 650-651).

Sanseverino afirma que os riscos do desenvolvimento deveriam ter sido elencados de maneira expressa do rol de causas de exclusão da responsabilidade do fornecedor, como ocorreu no direito comunitário europeu. Complementa sua posição ao afirmar que a aceitação da eximente representaria um retrocesso no regime de responsabilidade objetiva acolhido pelo direito brasileiro, pois atribuiria os efeitos nocivos dos riscos de desenvolvimento ao próprio consumidor (2010, p. 345-346).

Outro adepto da responsabilização do fornecedor nessa hipótese, Marcelo Junqueira Calixto argumenta que adotar os riscos de desenvolvimento como excludente seria subordinar a proteção do consumidor ao avanço científico, porém entende ser necessária a responsabilização por um lapso temporal de até 10 anos do lançamento do produto, para que o produtor não fique eternamente responsabilizado (2004, p. 243-251-252).

Importante o destaque do Enunciado 43 da I Jornada de Direito Civil do Conselho da Justiça Federal que assim dispõe: "a responsabilidade civil pelo fato do produto, prevista no art. 931 do novo Código Civil, também inclui os riscos do desenvolvimento".

Em contrapartida, favorável a tratar os riscos do desenvolvimento como excludente de responsabilidade está James Marins (apud SANSEVERINO, 2010), que entende não existir o 
defeito no produto, pois na época em que o produto foi colocado no mercado existia a segurança que dele legitimamente se esperava, conforme o artigo 12, § $1^{\circ}$, inciso III, do Código de Defesa do Consumidor. Acrescenta, ainda, que o fator político que marcou a elaboração da Diretiva 85/374/CEE instituiu como regra a responsabilização, bem como que por razões de ordem econômica, a grande carga de responsabilidade assumida pelo fornecedor viria em detrimento do próprio desenvolvimento social (MARINS apud CALIXTO, 2004, p. 225-226).

Gustavo Tepedino corrobora tal entendimento, por entender ser necessário tratar os riscos do desenvolvimento como excludente, no sentido de que inexiste o defeito do produto nessa hipótese:

O conceito de defeito é essencialmente relativo, antepondo duas noções, em determinado contexto histórico: segurança e expectativa dos consumidores. Assim, no risco de desenvolvimento, não existe defeito, por inexistir uma reversão de expectativa em face dos conhecimentos atuais. Não se pode esperar algo que se desconhece. Há, sim, neste caso, periculosidade ou nocividade, objetivamente consideradas, embora desconhecidas pela ciência no momento do oferecimento do produto ou serviço. (TEPEDINO, 2006, p. 114).

O debate torna-se ainda mais conflituoso pela escassa jurisprudência acerca dos riscos do desenvolvimento e danos tardios acometidos aos consumidores.

Na hipótese de danos tardios acometidos aos consumidores, como por exemplo danos à saúde causados pelo consumo de tabaco e de bebida alcóolica, a jurisprudência do Superior Tribunal de Justiça é no sentido de que não se trata de um produto defeituoso e sim de periculosidade inerente, com ampla divulgação pelos fornecedores dos malefícios causados, sendo uma escolha do consumidor a ingestão de tais produtos, o que afasta o dever de indenizar e a caracterização de risco do desenvolvimento. Tal posicionamento pode ser verificado no julgamento do Recurso Especial no 1322964 , de relatoria do Ministro Ricardo Villas Bôas Cueva, realizado em 22.05.2018, e no Recurso Especial no 1113804, de relatoria do Ministro Luis Felipe Salomão, julgado em 27.04.2010.

Caso os riscos de desenvolvimento sejam considerados com um risco inerente ao empreendimento, a jurisprudência é pacífica no sentido de responsabilização do fornecedor, como no Recurso Especial n 1599405, de relatoria do Ministro Marco Aurélio Bellizze, julgado em 04.04.2017:

O Código de Defesa do Consumidor acolheu a teoria do risco do empreendimento (ou da atividade) segundo a qual o fornecedor responde objetivamente por todos os danos causados ao consumidor pelo produto ou 
serviço que se revele defeituoso (ou com a pecha de defeituoso, em que o fornecedor não se desonera do ônus de comprovar que seu produto não ostenta o defeito a ele imputado), na medida em que a atividade econômica é desenvolvida, precipuamente, em seu benefício, devendo, pois, arcar com os riscos "de consumo" dela advindos.

A explanação conjunta da legislação, da doutrina e da jurisprudência permite uma melhor elucidação sobre o tema, de modo a ser possível analisar a viabilidade da adoção da teoria dos riscos do desenvolvimento como excludente de responsabilidade no ordenamento jurídico brasileiro.

\section{CONSIDERAÇÕES FINAIS}

Diante da necessidade de existir um posicionamento legislativo quanto à responsabilidade pelos riscos do desenvolvimento, é de se ver que, pela análise do ordenamento jurídico brasileiro, a solução mais adequada a ser adotada seria a responsabilização do fornecedor.

Inicialmente, faz-se necessária uma análise constitucional do tema, visto que a defesa do consumidor é prevista como garantia fundamental no ordenamento, cláusula pétrea presente no rol do artigo $5^{\circ}$, inciso XXXII. Também mencionada no artigo 170, a relação de consumo fica tutelada por todos os fundamentos e direitos indisponíveis da Carta Magna, como o direito à vida, à saúde e à dignidade da pessoa humana. Desse modo, transferir um dano causado pelo fabricante exclusivamente ao consumidor seria ir de encontro ao Texto Magno.

Por conseguinte, o Código de Defesa do Consumidor revela em sua base o princípio da garantia da adequação e principalmente o da vulnerabilidade, que objetiva justamente proteger o elo mais vulnerável quanto aos desequilíbrios na relação de consumo.

Citam-se ainda os direitos básicos presentes no artigo $6^{\circ}$ do Código, como a proteção da vida, da saúde, dos riscos provocados por práticas no fornecimento de produtos e serviços nocivos, bem como a prevenção e efetiva reparação contra todo tipo de dano, seja ele patrimonial, moral, coletivo ou difuso.

Com o advento da Lei 8.078/90, a responsabilidade civil tornou-se objetiva, baseada na teoria do risco do empreendimento, segundo a qual todo o fornecedor que se dispõe a lançar produtos e serviços no mercado deve garantir a qualidade de seus produtos e responder por danos e vícios decorrentes do que foi oferecido, independente de culpa, salvo as excludentes de responsabilidade existentes. Não estando os riscos do desenvolvimento no rol das excludentes, o fabricante não se exime do dever de indenizar. 
Por essa interpretação, a verificação de que o estado do avanço científico não seria hábil a verificar o defeito na época em que o produto foi inserido no mercado, traria novamente a discussão para o âmbito da culpa ou do dolo, afastando o sistema atualmente adotado em Lei.

Além disso, na eventual hipótese de se considerar os riscos do desenvolvimento como excludente, estaria vinculando-se a saúde e a defesa do consumidor ao estado da tecnologia da época, ideia contrária a todo o embasamento protetivo que a legislação traz consigo.

Para o fornecedor existem mecanismos para diluir os riscos, como pesquisas sobre o produto durante toda a elaboração, mecanismos de preços para poder distribuir os riscos para o mercado, seguros a serem contratados, além de poder fazer o recall de produtos, assim que verificada a falha, o que também estimula a empresa a uma busca pela tecnologia mais adequada e ao acompanhamento de seus produtos até o fim do seu ciclo de vida.

Sendo assim, conclui-se que a melhor alternativa para a questão, vindo ao encontro da legislação pátria, é a não adoção dos riscos do desenvolvimento como excludente de responsabilidade, devendo o fornecedor assumi-los no caso concreto.

\section{REFERÊNCIAS}

BARROSO, Luís Roberto. O novo direito constitucional brasileiro: contribuições para a construção teórica e prática da jurisdição constitucional no Brasil. Belo Horizonte: Editora Fórum, 2013.

BENJAMIN, Antônio Herman V.; BESSA, Leonardo Roscoe; MARQUES, Cláudia Lima. Manual de Direito do Consumidor. São Paulo: Revista dos Tribunais, 2014.

BRASIL. Conselho da Justiça Federal. I Jornada de Direito Civil, Brasília, DF, 05 de agosto de 2003. Disponível em: < https://www.cjf.jus.br/cjf/corregedoria-da-justica-federal/centro-deestudos-judiciarios-1/publicacoes-1/cjf/corregedoria-da-justica-federal/centro-de-estudos-

judiciarios-1/publicacoes-1/jornadas-cej/i-jornada-de-direito-civil.pdf $>$. Acesso em: $13 \mathrm{dez}$. 2019.

BRASIL. Constituição da República Federativa do Brasil de 1988, Brasília, DF, 05 de outubro de $1988 . \quad$ Disponível em: <http://www.planalto.gov.br/ccivil_03/constituicao/constituicaocompilado.htm>. Acesso em: 11 dez. 2019.

BRASIL. Lei no 8.078, de 11 de setembro de 1990. Código de Defesa do Consumidor. Diário Oficial da União, Brasília, DF, 12 de setembro de 1990. Disponível em: <http://www.planalto.gov.br/ccivil_03/leis/L8078.htm>. Acesso em: 11 dez. 2019.

BRASIL. Lei no 10.406, de 10 de janeiro de 2002. Código Civil. Diário Oficial da União, Brasília, DF, 11 de janeiro de 2002. Disponível em: <http://www.planalto.gov.br/ccivil_03/leis/2002/L10406.htm>. Acesso em: 11 dez. 2019. 
BRASIL. Superior Tribunal de Justiça. Disponível em: <http://www.stj.jus.br>. Acesso em: 11 dez. 2019.

CALIXTO, Marcelo Junqueira. A responsabilidade civil do fornecedor de produtos pelos riscos do desenvolvimento. Rio de Janeiro: Renovar, 2004.

CAVALIERI FILHO, Sergio. Programa de Responsabilidade Civil. São Paulo: Atlas, 2007.

CAVALIERI FILHO, Sergio. Programa de Direito do Consumidor. São Paulo: Atlas, 2010.

COMUNIDADE ECONÔMICA EUROPÉIA. Diretiva 85/374/CEE, de 25 de julho de 1985. Disponível em: <http://eur-lex.europa.eu/legal-content/PT/TXT/?uri=CELEX:31 985L0374\&from=PT>. Acesso em: 12 dez. 2019.

DIAS, Clara Angélica Gonçalves; CARVALHO, Ana Terra Teles de. RESPONSABILIDADE CIVIL DO ESTADO: BREVE PANORAMA EVOLUTIVO DO DIREITO BRASILEIRO. Revista Juridica, [S.1.], v. 3, n. 48, p. 335 - 357, set. 2017. ISSN 2316-753X. Disponível em: <http://revista.unicuritiba.edu.br/index.php/RevJur/article/view/2184/1364>. Acesso em: 18 abr. 2020. doi:http://dx.doi.org/10.21902/revistajur.2316-753X.v3i48.2184.

EFING, Antônio Carlos. Fundamentos do Direito das Relações de Consumo. Curitiba: Juruá, 2008.

GARCIA, Leonardo de Medeiros. Código de Defesa do Consumidor Comentado: artigo por artigo. $13^{a}$ edição. Salvador: JusPodivm, 2016.

GONÇALVES, Carlos Roberto. Responsabilidade Civil. 14ª edição. São Paulo: Saraiva, 2012.

KHOURI, Paulo Roberto Roque Antonio. Direito do consumidor: contratos, responsabilidade civil e defesa do consumidor em juízo. 4a edição. São Paulo: Atlas, 2009.

MARQUES, Cláudia Lima. Contratos no Código de Defesa do Consumidor: o novo regime das relações contratuais. São Paulo: Revista dos Tribunais, 2006.

MIRAGEM, Bruno. Curso de Direito do Consumidor. $7^{\text {a }}$. edição. São Paulo: Editora Thomson Reuters Revista dos Tribunais, 2018.

SANSEVERINO, Paulo de Tarso Vieira. Responsabilidade Civil no Código do Consumidor e a Defesa do Fornecedor. São Paulo: Saraiva, 2010.

STOCO, Rui. Tratado de responsabilidade civil: doutrina e jurisprudência. $8^{\text {a }}$. edição. São Paulo: Editora Revista dos Tribunais, 2011.

TEPEDINO, Gustavo. Temas de direito civil - Tomo II. Rio de Janeiro: Renovar, 2006.

THEODORO JÚNIOR, Humberto. Direitos do Consumidor. 9a edição. Rio de Janeiro: Editora Forense, 2017. 
VENOSA, Sílvio de Salvo. Direito Civil: obrigações e responsabilidade civil. $18^{a}$ edição. São Paulo: Editora Atlas, 2018. 